\title{
Polycystic Ovary Morphology (PCOM) in Estradiol Valerate Treated Mouse Model
}

\section{Leila Amini ${ }^{1}$, Najmeh Tehranian ${ }^{1 *}$, Mansoureh Movahedin ${ }^{2}$, Fahimeh Ramezani Tehrani ${ }^{3}$, Haleh Soltanghoraee}

\begin{abstract}
Objectives: Polycystic ovary syndrome (PCOS) is the most common endocrine disorder in women of reproductive age. Polycystic ovary (PCO) is a criterion for PCOS. Several animal models of polycystic ovary morphology (PCOM) are developed in order to study PCOS aspects. The present study aimed to develop a polycystic ovarian model in mice.

Materials and Methods: Thirty-four young adult female mice were divided equally into estradiol valerate (EV) treated and control groups. Mice in experimental group $(n=18)$ received a single dose injection of EV (IM, $4 \mathrm{mg} / \mathrm{kg})$. Weight and fertility rate of all mice were recorded. Morphology of ovarian follicles was assessed too. Chi-square and independent $t$ test were used for comparison between groups. $P$ value less than 0.05 was considered as significant level.

Results: After 60 days, the weight of EV-treated mice was significantly lower than control $(P<0.04)$ and the experimental group did not show any significant changes in their body weight. Fertility rate in experimental group was significantly lower $(P<0.001)$ than the other group. Follicle count showed that the number of preovulatory follicles and corpora lutea were lower $(P<0.001)$ and atretic follicles were higher $(P<0.001)$ significantly in EV-treated group in comparison to control. However, there were no significant differences in the number of primary, preantral and antral follicles between two groups.

Conclusion: The polycystic ovary morphology can be induced in adult mice with a single dose of EV. This model may help to improve our knowledge on all aspects of PCOS.

Keywords: Animal models, Estradiol valerate, Ovarian follicle, Polycystic ovary syndrome
\end{abstract}

\section{Introduction}

Polycystic ovary syndrome (PCOS) is one of the most common endocrinopathies found among 5\%-10\% of reproductive age women. It is a common cause of infertility due to anovulatory (1) and hyperandrogenism (2). The name of PCOS is based on ovarian morphological changes in women who suffer from menstrual disturbances and hyperandrogenism symptoms, so polycystic ovary morphology (PCOM) can be a notable feature of PCOS (3). PCOM is revealed by some ovarian morphological abnormalities such as polycystic and enlarged ovaries (4). Although many extra ovarian causes are raised in the pathophysiology of PCOS, ovarian dysfunction plays the most important role in this field (5). Although all women with PCOS are in risk of hormonal and glucose metabolism disturbances, insulin resistance, dyslipidemia, metabolic syndrome, cardiovascular disease, and endometrial hyperplasia (4), it seems that PCOS women with PCOM are in risk of elevated serum DHEA-S levels and also taking a higher daily dose of insulin in comparison to PCOS women without PCOM (6).
There are many hypotheses for the etiology of PCOS (7), but the exact initiating event in the pathophysiology of the syndrome is not entirely clear and remains poorly understood. Since the study of pathophysiology or any manipulation for treatment of PCOS/PCOM in human faces some serious logistic and ethical limitations; animal modeling is a good choice to improve the understanding of the abstruse aspects of PCOS (8). Since the 1960s, many animal models such as rodents, sheep and nonhuman primates have been applied for this purpose. Using the mouse models can provide an all-purpose tool for studying and understanding the comprehensive biologic mechanisms of PCOS/PCOM. They have stable genetic backgrounds, shorter reproductive and estrous cycle and generation times, and reasonably priced. Besides, these models have shown same reproductive and metabolic conditions as human PCOS (9).

Different procedures have been suggested to produce PCOS model including prenatal or pre-pubertal androgen exposure $(10,11)$, aromatase inhibitor or estradiol administration (11-13), and transgenic models (11). 
Exposure to a single dose of estradiol valerate (EV) in adult rat can cause irregular cycles, lack of ovulation and polycystic ovaries with high number of atretic follicles and cysts. These changes in ovarian morphological features are similar to those of PCOS women (9). The polycystic ovarian morphology in PCOS is presented by an excessive amount of growing follicles (13). In the present study we aimed to develop PCOM model through the EV-treated mice.

\section{Materials and Methods}

Animals and Experiment Design

Twenty-eight young adult virgin NMRI female mice (28$32 \mathrm{~g}, 8$ weeks old) from the animal house of the Tarbiat Modares University (Tehran, Iran) were kept in a central animal care room with temperature-controlled rooms $\left(22 \pm 2^{\circ} \mathrm{C}\right)$ and relative humidity (45\%-55\%), under a 12 hours on and 12 hours off light cycle. Each five of them were housed in to a cage with unlimited food and water access.

Hormonal Treatment and Study Procedure

All mice were equally divided in to two groups (experimental and control groups) for the next 60 days after EV treatment.

Control group $(n=14)$ mice did not receive any injection or other manipulations. Mice in experimental group $(\mathrm{n}=14)$ received an IM injection of $\mathrm{EV}(4 \mathrm{mg} / \mathrm{kg}$ dissolved in $0.4 \mathrm{ml}$ of sesame oil) (Aburaihan Co., Iran), to induce PCOM (14). Mice body weight was measured on the first day and 60th day of the study before removal of the ovaries.

Evaluation of Ovarian Morphology and Follicle Count Sixty days after the EV injection, the mice in two groups (7 in experiment and 7 in control groups) were anesthetized with ketamine and xylazine and their ovaries were removed and separated from other tissues. The ovaries were fixed at least for a day in formaldehyde $10 \%$. After tissue processing according to standard protocols, ovaries were imbedded and blocked in paraffin and longitudinally and serially cut in $5 \mu \mathrm{m}$ sections. For tissue staining, we used hematoxylin and eosin. Serial ovarian sections were observed under a light microscope (Olympus, Japan) ( $\times 100$ and $\times 40$ magnifications). Follicles were defined primary if had a single layer of cubidal granulosa cells; preantral if had one or two small spaces filled by follicular fluid; antral if had a single large antral space; preovulatory if oocyte was surrounded by a rim of cumulus cells (15); atretic if follicles were deformed or oocyte was absent or pyknotic nuclei presented in granulosa cells; and corpora lutea. All types of follicles were counted in each ovary. Then all follicles were classified as healthy (primary, preantral, antral and preovulatory) or atretic (16). All types of follicles, cysts, and corpus lutea in each ovary were counted by two persons within 9 representative sections at least $25 \mu \mathrm{m}$ apart.
Fertility Rate

Fertility rate was monitored and recorded in two groups. The seven remaining mice in each group were mated with male mice ( 2 male for each group) for the first 4 weeks after completion of the study. Since the male mice had not mated before, to avoid mating of mice with an infertile or subfertile male; male mice were exchanged between two groups after first the 15 days. All pregnancies and births were monitored and recorded too.

\section{Statistical Analysis}

Data are shown as mean \pm standard deviation or frequency and percent. Independent $t$ test or chi square test were used for group comparison. $P<0.05$ was considered as significant level. SPSS 14 (SPSS Inc, Chicago USA) was used for statistical analysis.

\section{Results}

Body Weight and Fertility Rate

Body weight of mice in two groups is shown in Table 1. There were no significant differences between two groups in baseline, but after 60 days, tangible weight gaining in control group $(P=0.031)$, was significantly more than experiment group. The experimental group did not show any significant changes in their body weight at the same time. Fertility rate was significantly lower ( $0 \%$ vs. $75 \%$ respectively, $P<0.001)$ in experimental vs. control group.

\section{Ovarian Histological Changes}

Histological analysis was performed on ovaries from EVtreated and control mice at the 60th day of study. The images are presented in Figure 1.

Follicle count showed a significant decrease in the number of preovulatory follicles and corpora lutea in the ovaries of experimental group in comparison to control $(P<0.001)$. However, there was no significance in the number of primary, preantral and antral follicles of experimental group in comparison to control. Surprisingly, the atretic follicles were about 3.5 folds higher in EV-treated than control group $(P<0.001$; Table 2, Figure 1). There was various degree of atresia in experimental group mice, from follicles with nuclear pyknosis to corpus fibrosum (CF). The results also showed a significant differences between two groups regarding corpora lutea (CL) to healthy follicles ratio $(P=0.005)$, and the ratio of atretic follicles to healthy follicles $(P<0.001$; Table 2$)$.

\section{Discussion}

PCOM, one of the three criteria for PCOS diagnosis (17), is surrounded by many questions. The answer to these questions need appropriate animal models, as the human studies are faced with some logistic and ethical limitations (8). Thus mouse models are good and affordable choice for this purpose (9). Numerous experimental models for PCOM have been developed using EV (18). EV can produce a PCOM model in rat with interrupting in metabolic and physiologic processes (19). 
Table 1. Body Weight of Experimental and Control Groups at Baseline and on 60th Day of Study

\begin{tabular}{|c|c|c|c|c|}
\hline & $\begin{array}{c}\text { Experimental Group } \\
n=7\end{array}$ & $\begin{array}{c}\text { Control Group } \\
n=7\end{array}$ & & \\
\hline & $\mathrm{M} \pm \mathrm{SD}$ & $\mathrm{M} \pm \mathrm{SD}$ & $\mathbf{t}$ & $P$ Value \\
\hline Baseline body weight (g) & $29.09 \pm 2.14$ & $30.50 \pm 0.707$ & -0.891 & 0.392 \\
\hline 60th day body weight (g) & $28.95 \pm 2.03$ & $35.04 \pm 1.53$ & -3.549 & 0.038 \\
\hline Test result & $\begin{array}{l}\mathrm{t}=-0.326 \\
P=0.761\end{array}$ & $\begin{array}{l}\mathrm{t}=-5.519 \\
P=0.031\end{array}$ & & \\
\hline
\end{tabular}

Table 2. The Number Of Follicles, CL, CL/H Ratio and Atretic to Healthy Ratio

\begin{tabular}{|c|c|c|c|c|}
\hline & $\begin{array}{c}\text { Experimental Group } \\
n=7\end{array}$ & $\begin{array}{c}\text { Control Group } \\
n=7\end{array}$ & $\mathrm{t}$ & $\boldsymbol{P}$ Value \\
\hline Per Section & $\mathrm{M} \pm \mathrm{SD}$ & $\mathrm{M} \pm \mathrm{SD}$ & & \\
\hline Number of primary follicles & $5.95 \pm 3.09$ & $6.40 \pm 2.84$ & 0.723 & 0.472 \\
\hline Number of preantral follicles & $1.09 \pm 0.75$ & $1.02 \pm 1.37$ & -0.316 & 0.753 \\
\hline Number of antral follicles & $3.14 \pm 2.59$ & $4.26 \pm 3.14$ & 1.836 & 0.07 \\
\hline Number of preovulatory follicles & $0.00 \pm 0.00$ & $0.26 \pm 0.44$ & 4.149 & 0.000 \\
\hline Number of $\mathrm{CL}$ & $2.38 \pm 2.56$ & $6.00 \pm 6.33$ & 5.750 & 0.000 \\
\hline Number of $A$ & $17.97 \pm 11.66$ & $4.78 \pm 3.39$ & -7.081 & 0.000 \\
\hline Number of $\mathrm{H}$ & $10.19 \pm 4.82$ & $11.94 \pm 3.95$ & 1.912 & 0.051 \\
\hline $\mathrm{CL} / \mathrm{H}$ Ratio & $0.33 \pm 0.46$ & $0.58 \pm 0.38$ & 2.884 & 0.005 \\
\hline A/H Ratio & $2.29 \pm 1.95$ & $0.43 \pm 0.33$ & 6.098 & 0.000 \\
\hline
\end{tabular}

Abbreviations: $\mathrm{CL}$, Corpora Lutea; A, Atretic follicles; $\mathrm{H}$, Healthy follicles.

In this study, morphological examination of the ovaries showed that exposure of young adult female mice to a single dose of exogenous EV can inhibit ovulation. Despite the lack of significant differences between the two groups regarding preantral and antral follicles, similar to other studies $(14,20,21)$, the preovulatory follicle and corpora lutea were significantly lower in EV-treated mice. This can be related to the reduced ovulatory rate or anovulation, explaining the poor fertility rate in this group. This finding is confirmed by Radavelli-Bagatini et al study (16). It seems these results may be due to increased serum estradiol concentration which can provide an inappropriate hormonal environment for developing follicles to be ovulated in very earliest stages of folliculogenesis (22). Impaired follicle growth appears to arise from increased luteinizing hormone (LH), low FSH secretion and androgen level elevation (23). Besides, EV can inhibit ovulatory cycles and induce growth hormone secretion and hypothalamic disturbances (24).

Interestingly, while the number of follicles did not show any significant differences between two groups, the number of atretic follicles were significantly higher in experimental group such that the ratio of atretic to healthy follicles also were higher in the EV-treated group in comparison with control mice.

Also, Brawer et al showed that EV can increase atretic or degenerative secondary follicles and decrease postovulatory corpora lutea in ovaries of rats (18). Stener-

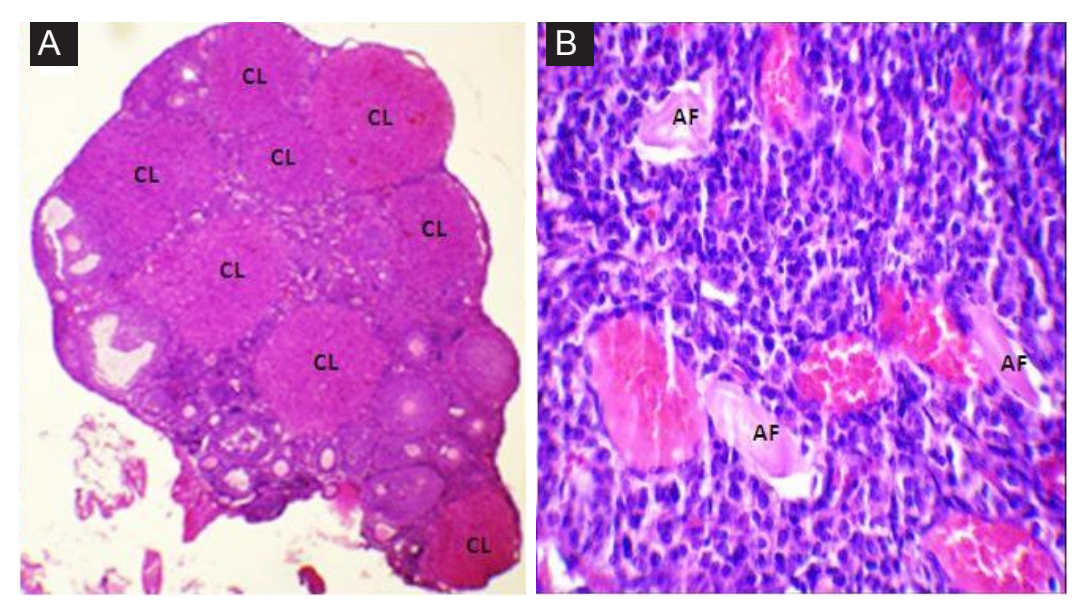

Figure 1. Ovarian Histology of Experimental and Control Mice. (A) ( $\times 40)$, ovarian tissue of a control mouse with several $C L ;(B)(\times 100)$, ovarian tissue of an EV-treated mouse. Abbreviations: AF, atretic follicle; $\mathrm{CL}$, corpora lutea. 
Victorin et al reported the same results in EV-treated rats after 60 days (22). These results are expected because polycystic ovary is a disorder of follicle development. In PCOM, follicles arrest in immature stages and therefore dominant follicle selection will not occur. This may be due to lack of positive estrogen feedback to the hypothalamus and pituitary axis. As the result of this lacking, LH surge will not occur and therefore ovulation will be disrupted (11). Zangeneh et al believe changes after single dose of EV administration can be due to the peripheral sympathetic neuron activation that innervates the ovaries. As a result of increasing sympathetic activity, PCOS will develop $(25,26)$.

Despite the fact that obesity and overweight are common in PCOS women (27), another finding of present study showed that the body weight in experimental group on the 60th day after EV injection, was significantly lower than control ones. Although the weight of control group was significantly increased within 60 days of study, but experimental group did not have any weight gain and instead their weight decreased slightly which was not statistically significant. Ikeda et al also found that the weight of DHEA treated rats on day-30 was lower than control group and DHEA group showed no increase in weight in comparison with day-15 (28). Other studies also showed a significantly lower weight in EV-treated rats in comparison with control group $(20,29)$. This weight loss is thought to be due to the lipolytic effects of adrenal glucocorticoids augmentation following EV injection. Besides some changes in hypothalamic paraventricular nucleus can prevent food intake in this group. On the other hand, this result might be explained by peripheral sympathetic neuron activation after administration of a single dose of EV that may be linked to metabolic activity promotion, increased fat consumption and consequently lack of weight gain (22). However, all patients with PCOS are not overweight or obese and there are many variations in body weight among different PCOS populations (27).

\section{Conclusion}

The result of present study showed that PCOM can be induced in adult mice with a single dose injection of EV. This easy handling mouse model may enable us to compare various treatment modalities. It is important to note that in this study we assessed the PCOM model not only with different follicle counts but also with fertility rate of mice.

\section{Ethical issues}

In this study, the mice were handled according to the experimental protocols and ethical principles of laboratory animal care approved and followed by the local committee of the Tarbiat Modares University (D 52/694 2013.5.11).

\section{Conflict of interests}

The authors declare no conflict of interests.

\section{Financial support}

The authors declare no financial and material sup $\neg$ ports in this project.

\section{Acknowledgments}

This research was derived from $\mathrm{PhD}$ thesis of reproductive health approved and funded by Medical Faculty of Tarbiat Modares University, Tehran, Iran. The authors want to address their special thanks to Ms. Soltani and Ms. AliAkbari for their sincere helps.

\section{References}

1. Rotterdam ESHRE/ASRM-Sponsored PCOS Consensus Workshop Group. Revised 2003 consensus on diagnostic criteria and long-term health risks related to polycystic ovary syndrome. Fertil Steril. 2004;81:19-25.

2. Norman RJ, Dewailly D, Legro RS, Hickey TE: Polycystic ovary syndrome. Lancet. 2007;370:685-97. doi:10.1016/s0140-6736(07)61345-2.

3. Alsamarai S, Adams JM, Murphy MK, et al. Criteria for polycystic ovarian morphology in polycystic ovary syndrome as a function of age. J Clin Endocrinol Metab. 2009;94(12):4961-70. doi:10.1210/jc.20090839.

4. Teede H, Deeks A, Moran L. Polycystic ovary syndrome: a complex condition with psychological, reproductive and metabolic manifestations that impacts on health across the lifespan. BMC Med. 2010;8:41. doi:10.1186/1741-7015-8-41.

5. Balen AH, Laven JSE, Tan SL, Dewailly D. Ultrasound assessment of the polycystic ovary: international consensus definitions. Hum Reprod Update. 2003;9(6):505-514. doi:10.1093/humupd/dmg044.

6. Miyoshi A, Nagai S, Takeda $M$, et al. Ovarian morphology and prevalence of polycystic ovary syndrome in Japanese women with type 1 diabetes mellitus. J Diabetes Inves. 2013;4(3):326-329. doi:10.1111/jdi.12040.

7. Marx TL, Mehta AE. Polycystic ovary syndrome: Pathogenesis and treatment over the short and long term. Cleve Clin J Med. 2003;70(1):31-45. doi:10.3949/ccjm.70.1.31.

8. Mahajan DK. Polycystic ovarian disease: animal models. Endocrinol Metab Clin North Am. 1988;17(4):705-732.

9. Walters KA, Allan CM, Handelsman DJ. Rodent models for human polycystic ovary syndrome. Biol Reprod. 2012;86(5):149. doi:10.1095/ biolreprod.111.097808.

10. Ramezani Tehrani F, Noroozzadeh M, Zahediasl S, Piryaei A, Azizi F. Introducing a rat model of prenatal androgen-induced polycystic ovary syndrome in adulthood. Exp Physiol. 2014; 99(5):792-801. doi:10.1113/expphysiol.2014.078055

11. Oakley O, Lin P, Bridges P, Ko C. Animal models 
for the study of polycystic ovarian syndrome. Endocrinol Metab. 2011;26(3):193-202. doi:10.3803/ enm.2011.26.3.193.

12. Maharjan R, Nagar PS, Nampoothiri L. Effect of Aloe barbadensis Mill. formulation on Letrozole induced polycystic ovarian syndrome rat model. J Ayurveda Integr Med. 2010;1(4):273-279. doi:10.4103/09759476.74090 .

13. Chapman JC, Min SH, Freeh SM, Michael SD. The estrogen-injected female mouse: new insight into the etiology of PCOS. Reprod Biol Endocrinol. 2009;7(1):47. doi:10.1186/1477-7827-7-47.

14. Noorafshan A, Ahmadi M, Mesbah S, Karbalay-Doust S. Stereological study of the effects of letrozole and estradiol valerate treatment on the ovary of rats. Clin Exp Reprod Med. 2013;40(3):115-121. doi:10.5653/ cerm.2013.40.3.115.

15. Myers M, Britt KL, Wreford NGM, Ebling FJP, Kerr JB. Methods for quantifying follicular numbers within the mouse ovary. Reproduction. 2004;127(5):569580.

16. Radavelli-Bagatini S, Blair AR, Proietto J, Spritzer PM, Andrikopoulos S. The New Zealand obese mouse model of obesity insulin resistance and poor breeding performance: evaluation of ovarian structure and function. J Endocrinol. 2011;209(3):307-315.

17. Porter MB. Polycystic ovary syndrome: The controversy of diagnosis by ultrasound. Semin Reprod Med. 2008; 26(3):241-51.

18. Brawer JR, Munoz M, Farookhi R. Development of the polycystic ovarian condition (PCO) in the estradiol valerate-treated rat. Biol Reprod. 1986;35(3):647-655.

19. Atis A, Aydin Y, Ciftci F, et al. Hyberbaric oxygen increases atresia in normal \& steroid induced PCO rat ovaries. Reprod Biol Endocrinol. 2012;10(1):1-8.

20. van Houten EL, Kramer P, McLuskey A, Karels B, Themmen AP, Visser JA. Reproductive and metabolic phenotype of a mouse model of PCOS. Endocrinology. 2012; 153(6):2861-2869.

21. Yaba A, Demir N. The mechanism of mTOR (mammalian target of rapamycin) in a mouse model of polycystic ovary syndrome (PCOS). J Ova Res. 2012;5(1):1-2.

22. Stener-Victorin E, Ploj K, Larsson BM, Holmäng A. Rats with steroid-induced polycystic ovaries develops hypertension and increased sympathetic nervous system activity. Reproductive Biol Endocrinol. 2005;3(1):44.

23. Johansson J, Stener-Victorin E. Polycystic ovary syndrome: Effect and mechanisms of acupuncture for ovulation induction. Evidence-Based Complementary and Alternative Medicine. 2013;2013:762615.

24. Azziz R, Nestler JE, Dewailly D. Androgen excess disorders in women: Polycystic ovary syndrome and other disorders. 2nd ed. Totowa, New Jersey: Humana Press; 2006.

25. Zangeneh FZ, Naghizadeh MM, Minaee B, Aminee F. PCOS \& symptomatic outcome: role of the central and peripheral nervous system in ovarian function of rat. Asian J Pharm Clin Res. 2012;5(2):26-32.

26. Lara HE, Ferruz JL, Luza S, Bustamante DA, Borges Y, Ojeda SR. Activation of ovarian sympathetic nerves in polycystic ovary syndrome. Endocrinology. 1993;133(6):2690-2695. doi:10.1210/ endo.133.6.7902268.

27. Norman RJ, Noakes M, Wu R, Davies MJ, Moran L, Wang JX. Improving reproductive performance in overweight/obese women with effective weight management. Hum Reprod Update. 2004;10(3):267280. doi:10.1093/humupd/dmh018.

28. Ikeda $\mathrm{K}$, Baba $\mathrm{T}$, Morishita $\mathrm{M}$, et al. Long-term treatment with dehydroepiandrosterone may lead to follicular atresia through interaction with anti-Mullerian hormone. J Ova Res. 2014;7:46. doi:10.1186/1757-2215-7-46

29. Mesbah F, Moslem M, Vojdani Z, Mirkhani H. Estradiol valerate-induced polycystic ovary syndrome: an animal model study. ArmaghaneDanesh. 2011;15(4):325-334. [In Persian].

Copyright $\odot 2016$ The Author(s); This is an open-access article distributed under the terms of the Creative Commons Attribution License (http://creativecommons.org/licenses/by/4.0), which permits unrestricted use, distribution, and reproduction in any medium, provided the original work is properly cited. 